\section{Acute myeloid and monocytic leukaemia and benzene exposure in petroleum distribution workers in the United Kingdom}

EDITOR,-We read the paper by Rushton and Romaniuk $^{1}$ with much interest, and were particularly pleased to see that leukaemia data were analysed by cell type, as we have recommended on several occasions. However, we wish to comment on the quality of the data in the study, particularly the employment histories, and to discuss several methodological issues. We have previously reviewed earlier versions of the same report submitted to the Institute of Petroleum in the United Kingdom..$^{2-5}$ We thought that the quality of the data in the study needed a close scrutiny, and suggested to Rushton that sensitivity analyses be done. Although some sensitivity analyses have subsequently been conducted, we think that several areas still need clarification and that some limitations of the data need to be made more explicit.

Included in the final analysis were 90 leukaemia cases (table 3 in the published paper $^{1}$ ). Sensitivity analysis for all leukaemia was not presented in the published paper, but in the final University of Nottingham report. ${ }^{5}$ The employment histories of only 48 cases were based on personnel records (table 1 in appendix 3$).^{5}$ That is, only about $53 \%$ of the cases' complete employment histories (job titles, departments, and dates) were based on personnel records. The employment histories of the remaining $47 \%$ of the cases were reconstructed or "synthesised" from sources such as recall, interviews, entries in medical records, etc. Similarly, the work histories of only 55\% (193/354) of controls were based on complete personnel records. Furthermore, although these percentages for the cases and controls in the entire study seemed comparable, this was not true for some important subcohort analyses.

An example was the analysis for acute myeloid and monocytic leukaemia (AMML). Table 1 presents the number of cases of AMML and their controls, and odds ratios (ORs) by cumulative exposure category in the analyses based on all subjects (regardless of quality of employment histories) and on subjects whose employment histories were based on personnel records only, which served as a sensitivity analysis. Based on the analysis of all subjects (regardless of quality of employment histories), the authors found an increased OR of 2.82 (non-significant at the 0.05 level) for cumulative exposure of 4.5-44.9 ppm-years, and put much emphasis on this finding.

\section{CORRESPONDENCE}

However, of the nine cases assumed to have 4.5-44.9 ppm-years, the employment histories of only two $(22 \%)$ were based on personnel records. Furthermore, there was a strong possibility of differential bias between the cases and controls in this exposure category, as the employment histories of $65 \%(15 / 23)$ controls were based on personnel records.

If the analysis was restricted to workers with complete employment histories from personnel records, the OR for the $\geqslant 4.5$ ppm-year group was 0.33 (table 1 ). Clearly the excess based on all subjects came from those workers with employment histories of poorer quality. Based on tables 5 and 7 in the published paper, ${ }^{1}$ we have constructed a $2 \times 2$ table for those whose employment histories were synthesised from sources other than personnel records (table 2), and conducted an unmatched analysis. The OR (95\% CI) based on the Mantel-Haenszel procedure was $11.7(1.2-111.0)$. Thus, the group with synthesised employment histories based on poorly documented sources (such as personal recall, interviews, entries in medical records, etc) showed an extremely high risk, which was completely inconsistent with that derived from the analysis restricted to employment histories documented in personnel records. Therefore, this analysis, even if it does not completely invalidate the analysis in table 5 in the published paper, ${ }^{1}$ should at least provide some perspectives to the importance of the sensitivity analysis. This analysis also indicates that the statement in the abstract that "Analyses exploring the sensitivity of the results to the source and quality of the work histories showed similar patterns in general" ${ }^{1}$ is not valid at all in the case of the result for AMML.

Rushton and Romaniuk seemed to downplay the sensitivity analysis for AMML by arguing that the number in the analysis based on personnel records only was greatly reduced, implying that the sensitivity analysis was not reliable. That is precisely the point of a sensitivity analysis: there were few reliable data on employment histories in the group with cumulative exposure of $>4.5$ ppm-years (only two cases with complete employment histories from personnel records).

The finding for AMML of an increased OR of 2.82 for the 4.5-44.9 ppm-year cumulative exposure group was further weakened by the lack of internal consistency, even if we were to ignore the source or quality of employment history data. For example, the model treating cumulative exposure as a continuous variable did not find any increased risk (OR 1.00, 95\% CI 0.96-1.04). ${ }^{1}$ In general, a model based on continuous variables is more informative and less vulnerable to artifacts created by categorisation. Analyses based on grouped data can be influenced heavily by the grouping itself (how the categories were chosen). Furthermore, in many of the 50 models on AMML presented in the earlier report dated

Table 1 Risk of acute myeloid and monocytic leukaemia by source of employment history

\begin{tabular}{|c|c|c|c|c|c|c|c|c|}
\hline \multirow{2}{*}{$\begin{array}{l}\text { Cumulative } \\
\text { exposure (ppm-y) }\end{array}$} & \multicolumn{3}{|c|}{ All subjects } & \multicolumn{5}{|c|}{ Subjects with personnel records } \\
\hline & Cases & Controls & $O R$ & Case & & Cor & & $O R$ \\
\hline$<0.45$ & 7 & 46 & (1) & 6 & $86 \%$ & 31 & $67 \%$ & (1) \\
\hline $0.45-4.49$ & 15 & 51 & 2.17 & 12 & $80 \%$ & 26 & $51 \%$ & 1.42 \\
\hline $4.5-44.9$ & 9 & 23 & 2.82 & 2 & $22 \%$ & 15 & $65 \%$ & 0.33 \\
\hline$\geqslant 45$ & 0 & 1 & 0 & 0 & - & 0 & - & \\
\hline Total & 31 & 120 & - & 20 & $64 \%$ & 72 & $60 \%$ & - \\
\hline
\end{tabular}

Table 2 Two by two table for workers with synthesised employment histories

\begin{tabular}{llcl}
\hline Cumulative exposure & Cases & Controls & Total \\
\hline$>4.5$ ppm-y & 7 & 9 & 16 \\
$<0.45$ ppm-y & 1 & 15 & 16 \\
Total & 8 & 24 & 32 \\
\hline
\end{tabular}

April, $1995,{ }^{3}$ no increased risk was found for cumulative exposure of $>4.5$ ppm-years. Unfortunately these models were not presented, nor were their results discussed in the published paper by Rushton and Romaniuk. ${ }^{1}$

Furthermore, as in any historical exposure estimates, the accompanying exposure assessment introduced additional uncertainties. Unfortunately, all the uncertainties in employment histories and exposure assessment seemed to have been lost in the statistical manipulation of the data. For example, the authors attempted several analyses to discriminate potential difference in risk resulting from exposure to $0.2,0.3$, or $0.4 \mathrm{ppm}$. We doubt very much that the quality of the employment and exposure data in the study warranted such a fine distinction. In fact, we question whether measurements in the early part of the study period, even if such data were available, were that precise. To infer a difference of $0.1 \mathrm{ppm}$ even for a single person, would require multiple samples. The level of analysis was inappropriate given the uncertainties of the original data. No mathematical manipulation could reduce the uncertainties of the original data.

Another problem in the paper ${ }^{1}$ is the multiple comparison issue. An extremely large number of risk estimates were calculated, and not every estimate was presented in the published paper. For example, according to the earlier report dated April, 1995, ${ }^{3} 50$ models were used in analysing the AMML data, which consisted of 32 cases. In these 50 models for AMML, about 110 ORs were calculated. In the entire report, close to 300 ORs, not counting those for sensitivity analyses, were presented. With this many ORs calculated, several would be significant due to chance alone. Indeed, the authors themselves recognised the multiple comparison problem, and labelled the entire investigation as "hypothesis generating" in the earlier reports. ${ }^{3}$ Unfortunately, for no stated reason, the label hypothesis generating was dropped in the published version of the report. ${ }^{1}$

In summary, the interpretation of Rushton and Romaniuk that exposure to low concentrations of benzene in the range of 4.5-45 ppm-years could increase the risk of developing AMML was not justified for reasons already discussed. Peto at the Institute of Cancer Research (London), a reviewer of an earlier version of the Rushton and Romaniuk report, ${ }^{5}$ summarised his comments on the report as follows. "Many employment histories are seriously incomplete, and it is possible that the construction of exposure measures was biased in some way." "This unexplained result (of a marked increase of chronic lymphatic leukaemia for the status of "still being in employment") ... cannot be due to benzene, (and) it casts doubt on the reliability of the findings related to benzene." "There is no clear evidence of any effect of benzene." (Peto J. Comments on the Institute of Petroleum benzene study. 24 July 1995. Unpublished report.) We could not have 
agreed more with Peto's summary of the Rushton and Romaniuk paper.

OTTO WONG Applied Health Sciences, 181 Second Avenue, Suite 628, PO Box 2078, San Mateo, California 94401 ,

USA

GERHARD K RAABE

Mobil Business Resources Corporation, Global Medical Services, PO Box 189, New Hope, Pennsylvania 18938, USA

Correspondence to: Otto Wong, Applied Health Sciences, 181 Second Avenue, Suite 628, PO Box 2078, San Mateo, California 94401, USA. Tel: 001 650347 7898; Fax: 0016503446887.

1 Rushton L, Romaniuk H. A case-control study to investigate the risk of leukemia associated with exposure to benzene in petroleum marketing and distribution workers in the United Kingdom. Occup Environ Med 1997;54:15266.

2 Rushton L, Romaniuk H. Results of a case-control study to investigate the risk of leukemia with exposure to benzene. Nottingham: University of Nottingham, March, 1995.

3 Rushton L, Romaniuk H. Results of a case-control study to investigate the risk of leukemia associated with exposure to benzene in petroleum marketing and distribution workers in the United Kingdom. 1995.

4 Rushton L, Romaniuk H. Results of a case-control study to investigate the risk of leukemia associated with exposure to benzene in petroleum marketing and distribution workers in the United Kingdom. Nottingham: University of Nottingham, June, 1995.

5 Rushton L, Romaniuk H. Results of a case-control study to investigate the risk of leukemia associated with exposure to benzene in petroleum marketing with exposure to benzene in petroleum marketing Nottingham: University of Nottingham, August, 1995.

Authors' reply-Occupational studies are often hampered by less than perfect data Wong and Raabe continue to place emphasis on the work history information in our nested case control study of leukaemia in oil distribution workers and exposure to benzene. However, as we have discussed at length in our paper, as well as deficiencies in these data, there were other limitations, including the quality of the information on distribution terminals and inconsistencies in some of the analyses.

We think it is important to point out that the final report submitted to the Institute of Petroleum took account of comments (sometimes conflicting) from very many people, including independent reviewers from outside the oil industry. The paper gave the main findings from the report, but space precluded presentation of all available tables.

Wong and Raabe focus on only one of the four sensitivity analyses carried out on the quality of the work histories, that including only cases and controls for whom a personne record was still in existence. Their unmatched analysis in table 2 is inappropriate as the study cases and controls were matched. They do not comment on the other three sensitivity analyses for which results tend to be similar to those for the total sample. They seem to be confusing the quality of information compared with the source of information. As we point out in our discussion, use of work histories from only existing personnel records excluded much good quality and reliable information from other sources.

Although not wishing to encourage selective quoting from unpublished material, Peto, in the covering letter of his review, also commented "the study seems to have been very well conducted and analysed". We are tempted to ask why Wong andRaabe continue to devote so much effort to seeking to estab- lish that benzene exposure is associated with no risk, by criticising a paper, the conclusions of the summary of which state "There is no evidence in this study of an association between exposure to benzene and lymphoid leukaemia, either acute or chronic.... However, in view of the limitations of the study, doubt remains as to whether the risk of acute myeloid and monocytic leukaemia is increased by cumulative exposures of $<45$ ppm-years. Further work is recommended to review the work histories and redefine their quality, to explore the discrepancies between results for categorical and continuous variables, and to develop ranges around the exposure estimates to enable further sensitivity analyses to be carried out."

LESLEY RUSHTON HELENA ROMANIUK Department of Public Health Medicine and Epidemiology, University of Nottingham, Queen's Medical Centre, Nottingham NG7 2UH

1 Rushton L, Romaniuk H. Results of an Casecontrol study to investigate the risks of leukaemia associated with exposure to benzene in petroleum marketing and distribution benzene in petroleum Kingdom. London: Institute of Petroleoum, Kingdom.
1995.

\section{Occupational asthma due to amylase}

EDITOR,-In their report on occupational asthma due to porcine pancreatic amylase, ${ }^{1}$ Aiken et al state that occupational asthma specifically due to amylase has only been described previously in bakers, and quoted a 1986 paper by Baur et al. ${ }^{2}$

In 1979, I reported five patients with asthma due to powdered $\alpha$-amylase (derived from Aspergillus oryzae). ${ }^{3}$ All gave positive skin prick tests (and subsequently positive RAST tests). Three were process workers, engaged in diluting enzyme concentrate with a carrier powder for the bakery trade; one worked in a laboratory doing quality control assay; and one worked in an office immediately above the enzyme mixing plant.

Hitherto, reported cases of enzyme sensitisation and asthma had been due to proteases, such as subtilopeptidase ${ }^{4}$ and papain, ${ }^{5}$ but this finding with $\alpha$-amylase confirmed the likelihood that enzymes were sensitisers by virtue of their being high molecular weight proteins irrespective of their specificity. ${ }^{6}$ The recommendation that all enzymes must be assumed to be allergenic has recently been strikingly endorsed in a study by Johnsen et al of workers exposed to proteases, lipases, cellulases, and carboxyhydrases. ${ }^{7}$

MICHAEL L H FLINDT Lowridding, Sedbergh, Cumbria, LA10 5LU, UK

1 Aiken TC, Ward R, Peel ET, et al. Occupational asthma due to porcine pancreatic amylase. asthma due to porcine pancreatic
Occup Environ Med 1997;54:762-4.

2 Baur K, Fruhmann G, Haug B, et al. Role of Aspergillus amylase in Baker's asthma. Lancet 1986;i:43.

3 Flindt MLH. Allergy to $\alpha$-amylase and papain. Lancet 1979:i:1407-8.

4 Flindt MLH. Pulmonary disease due to the inhalation of derivatives of Bacillus subtilis containing proteolytic enzyme. Lancet 1969; 1177-81.

5 Flindt MLH. Respiratory hazards from papain. Lancet 1978;i:430-2.

6 Flindt MLH. Health and safety aspects of working with enzymes. Process Biochemistry 1978; ing with en:

7 Johnsen CR, Sorensen TB, Larsen AI, et al. Allergy risk in an enzyme producing plant. Occup Environ Med 1997;54:671-5.
Author's reply - Flindt admonishes us for failing to accord precedence to him for recognising amylase induced occupational asthma outside the baking industry. We apologise for our inadequate literature search, and we are very happy to acknowledge Flindt's earlier contribution of 1979 to the relevant literature. In fact, his invaluable work with enzymes was well known to us, although we had failed to review his particular letter to the Lancet of 1979.

In this he reported, for the first time, evidence of immunological sensitivity to $\alpha$-amylase. $\mathrm{He}$ also augmented existing evidence of occupational sensitisation to the proteolytic enzyme papain. He argued that clinical symptoms in workers exposed to proteolytic enzymes were not primarily a consequence of proteolytic activity, but of allergenicity of enzymes in general because of their large molecular weights. The findings of skin reactions and symptoms in workers exposed to the non-proteolytic enzyme, $\alpha$-amylase, therefore supported this hypothesis. He reported investigations on eight people who had "rhinitis and/or asthma", of whom seven gave positive skin prick test reactions to papain and five to $\alpha$-amylase. Only one reacted to $\alpha$-amylase alone, but the table in his letter in the Lancet indicated that this person did have chest symptoms. No inhalation provocation tests were reported, and so it is questionable whether such an association provides adequate evidence of causality.

In his letter in response to our article, Flindt indicates that the five people with apparent sensitisation to $\alpha$-amylase were in fact working to produce the enzyme for the bakery trade, although they were not actually bakers. Our inadequately researched statement that "occupational asthma specifically due to amylase has only been described previously in bakers" may not therefore have been too misleading or unduly inaccurate.

DAVID J HENDRICK Royal Victoria Infirmary, Queen Victoria Road, Newcastle upon Tyne NE1 4LP, UK.

1 Flindt MLH. Allergy to $\alpha$-amylase and papain. Lancet 1979; i:1407-8.

\section{Dynamite plunger plots should not be} used

EDIToR,-The function of graphical displays is to offer information globally through one only sight. In some occasions, however, they can produce misleading impressions leading to erroneous interpretations. ${ }^{1}$ It has been suggested that, within reason, the ratio of the amount of information should be maximised to the amount of ink.

Bar charts showing the mean value with its error bar, usually referred to as a "dynamite plunger plot" have appeared in several papers of your fournal during the past year. ${ }^{3-7}$ Error bars, however, are not universally defined. They are usually based on the standard error (SEM), which sometimes may be chosen because it is smaller than alternatives such as the standard deviation (SD), leading to confusion of the reader. This type of presentation is to be avoided as it violates Tuffte's principle $^{2}$ in that only two numbers are conveyed with a large amount of ink, and any sense of the distribution of the data is lost.

For quantitative data alternative graphical displays - such as dot plots or box and whisker plots, have been suggested instead of dynamite plunger plots. ${ }^{8}$ Dot plots show the distribution of continuous data, if the sample 
size is small (say <50), presenting all the information economically. Box and whisker plots present in ascending order the minimum value, the first quartile, the median, the third quartile and the maximum value. These values are enough to convey the main points about the distribution of the data, also showing the possible outliers.

It is important to construct graphical representations of a publication avoiding too simplistic figures - such as dynamite plunger plots. ${ }^{9}$ This plot does not convey adequately the distribution of the data, and may lead to confusion in the interpretation of the results.

AURELIO TOBIAS

Medical Statistician, Research Unit of Respiratory and Enviromental Health, Institut Municipal d'Investigacio Medica (IMIM), Barcelona, Spain. email ATOBIAS@IMIM.ES

1 Huff D. How to lie with statistics. London Penguin, 1973.

2 Tufte ER. The visual display of quantitative information. Cheshire, Connecticut: Graphics Press, mation.

3 Egan CE, Espie BH, McGrann S, et al. Acutte effects of vibration on peripheral blood flow in healthy subjects. Occup Environ Med 1996;53. 663-9.

4 Rosa RR, Hõrmõ M, Pulli K, et al. Rescheduling a three shift system at a steel rolling mill: effects of a one hour delay of shift starting times on sleep and alertness in younger and older workers. Occup Environ Med 1996;53:667-85.

5 Gilmour PS, Brown DM, Lindsay TG, et al. Adverse effects of $\mathrm{PM}_{10}$ particles: involvement of iron in generation of hydroxyl radical. Occup Environ Med 1996;53:817-22.

6 Clottens FL, Verbeken EK, Demedts M, et al. Pulmonary toxicity of components of textile Pulmonary toxicity of components of textile paint linked to the Ardystil syndrome: intratracheal administration in ham

7 Nortier J, Bernard A, Roels H, et al. Urinary neutral endopeptidase in workers exposed to neutral endopeptidase in workers exposed to cadmiun: interaction with cigarette
Occup Environ Med 1997;54:432-6.

Occup Environ Med 1997;54:432-6.
8 Campbell MJ, Machin D. Medical statistics: a common sense approach. Chichester: Wiley, 1993.

9 Campbell MJ. Presenting numerical results. In Reece D, ed. How to do it. Vol 2. Examinations, academia, research, and communication. London: BMJ Publishing Group, 1995:77-83.

\section{NOTICES}

3rd International Scientific Conference on Prevention of Work Related Musculoskeletal Disorders

13th International Symposium on Epidemiology in Occupational Health

PREMUS-ISEOH'98. 21-25 September 1998. Marina Congress Center, Helsinki, Finland.

General:

- Work related disorders in various professional groups

- Exposure assessment
- Health assessment

- Methodological aspects

- Intervention studies

- Health surveillance

- Hazard surveillance

Prevention of work related

musculoskeletal disorders:

- Classification of musculoskeletal disorders

- Low back disorders

- Neck shoulder disorders

- Upper and lower extremity disorders

- Pathomechanisms of musculoskeletal disorders

- Biomechanical aspects of musculoskeletal disorders

Epidemiology in occupational health:

- Occupational cancer

- Cardiovascular diseases

- Respiratory diseases

- Reproductiove effects

- Neurobehavioural diseases

- Cytotoxins and solvents

- Noise

- Communicable diseases

- Accidents at work

Contact:

Ms Mirja Kallio, Finnish Institute of Occupational Health, Topeliuksenkatu 41 a A, FIN-00250 Helsinki, Finland. Tel: 00358 9 47471; Fax: 0035994747 548; email: mkal@occuphealth.fi; Internet: http// www.occuphealth.fi/eng/project/premus

International collaboration in research, education and training, and public policy in environmental and occupational health. 19-23 October, 1998. Natcher Center, National Institutes of Health, Bethesda, Maryland.

The 1998 SOEH meeting is organised by the Society for Occupational and Environmental Health in association with The John E Fogarty International Center for Advanced Study in the Health Sciences and World Health Organization Office of Global Environmental Health.

Environmental and occupational health professionals in the United States and other developed countries increasingly recognise the need to collaborate with colleagues in developing countries to advance shared goals in research, education and training, and public policy.

This meeting will bring together environmental and occupational health researchers, educators, and practitioners from industrialised countries, their counterparts from developing countries, and representatives of many agencies and institutions.
- To identify opportunities for collaborative research, education and training, and public policy

- To learn about collaborative projects and meet potential collaborators from many countries

- To speak with representatives of major funding agencies and foundations.

For Information contact: SOEH, ATTN: Marge Degnon, 6728 Old McLean Village Road, McLean, VA 22101, USA. Tel: 001 703556 9222, Fax: 0017035568729.

\section{XVth World Congress on Occupational} Safety and Health: a Global Challenge. 12-16 April 1999. São Paulo, Brazil.

This congress is organised by the Ministry of Labour of Brazil through FUNDACENTRO and the Secretariat of Occupational Safety and Health, the International Labour Office (ILO) in Geneva, and the International Social Security Association (ISSA) in Geneva. The Congress will provide in a worldwide forum unique opportunities for experts form regional bodies, such as MERCOSUL, NAFTA, the European Union, and others representing regional concerns, to meet and discuss individual approaches, experiences, and solutions found for protecting mankind and the environment and to deliberate their interrelation.

Besides the thorough and in depth coverage of the overall theme of the Congress "Safety, health and environment: a global challenge", the innovative concept for this Congress aims at:

- Providing participants with dynamic perspectives on how to anticipate and adapt to changes in the world

- Providing maximum interaction among all those involved or interested in prevention through their exchanges of views and experiences in personal contacts and through oral and poster corner presentations.

4th International film and video festival The 4th International film and video festival on occupational safety and health, will be held within the framework of the Congress, organised by the ISSA International Section "Electricity".

As in previous Congresses, a worldwide review of the current film and video productions will be provided. Films and videos will be described in a multilingual register. An international jury will award the best films and videos.

Further information from: Secretaria de XV Congresso Mundial Sobre Segurança e Saúde no Trabalho Fundacentro, Rua Capote Valente 710, 05409-002 São Paulo, SP, Brazil. 